\title{
Detection of Drought-Induced Hickory Disturbances in Western Lin An County, China, Using Multitemporal Landsat Imagery
}

\author{
Zhenyuan Xi, Dengsheng Lu *, Lijuan Liu and Hongli Ge
}

Key Laboratory of Carbon Cycling in Forest Ecosystems and Carbon Sequestration of Zhejiang, School of Environmental and Resource Sciences, Zhejiang Agriculture and Forestry University, Lin An 311300, China; zhenyuanxi2016@sina.com (Z.X.); 1lj7885@163.com (L.L.); jhghlhxl@163.com (H.G.)

* Correspondence: luds@zafu.edu.cn; Tel./Fax: +86-571-6374-6366

Academic Editors: Xiangming Xiao, Jinwei Dong, Parth Sarathi Roy and Prasad S. Thenkabail Received: 15 December 2015; Accepted: 4 April 2016; Published: 20 April 2016

\begin{abstract}
Hickory plantations play an important role in improving local farmers' economic conditions, but extreme drought in July-August 2013 seriously influenced hickory nut production. It is necessary to understand the extent and magnitude of this drought-induced hickory disturbance through mapping its spatial distribution using remote sensing data. This paper proposes a new approach to examine hickory disturbance based on multitemporal Landsat imagery. Ratios of green vegetation to soil fractions were calculated, in which the green vegetation and soil fractions were extracted from Landsat multispectral imagery using the linear spectral mixture analysis approach. We used the differences between before-drought and after-drought ratios to detect hickory disturbances. Four disturbance levels-non-disturbance, light, medium, and severe-were grouped according to the field survey data. The spatial distribution of these four levels was developed using the ratio-based approach. The result indicates that this approach is effective to detect drought-induced hickory disturbance and may be transferred to detect other kinds of disturbances, such as forest disease and selective logging. Cautions should be taken to properly select image acquisition dates and the change detection period, in addition to the approach itself.
\end{abstract}

Keywords: hickory plantation; drought-induced disturbance; Landsat; linear spectral mixture analysis; ratio of green vegetation to soil fractions

\section{Introduction}

Hickory (Carya cathayensis) was originally located in the region between Zhejiang and Anhui provinces, but it has now expanded to a wider region, including Guangxi Province in South China because of its important economic values. Hickory is a deciduous broadleaf forest, and hickory plantations have some unique characteristics (see Figure 1): (1) single tree species without or with little understory, relatively simple canopy structure, and less canopy density compared to other broadleaf forests; (2) mainly distributed on relatively steep slopes; and (3) intensive forest management, including adding nutrients and conducting grass removal a couple times every year. Due to its rapid expansion associated with intensive management (e.g., fertilization, weed control, use of insecticides), hickory plantations have produced serious environmental problems, such as soil erosion and water pollution [1].

The quality and quantity of hickory nuts are influenced by different factors such as tree disease, extreme weather, and improper management (e.g., over-fertilization). The extremely high temperatures with little rainfall (drought) in July-August 2013 severely influenced the health of hickory plantations, resulting in a considerable reduction of the hickory nut production in 2013 and 2014 (personal 
communication with hickory plantation owner). An urgently needed task was to develop an approach to rapidly map the spatial distribution of this drought-induced hickory disturbance in order to understand its extent and magnitude.

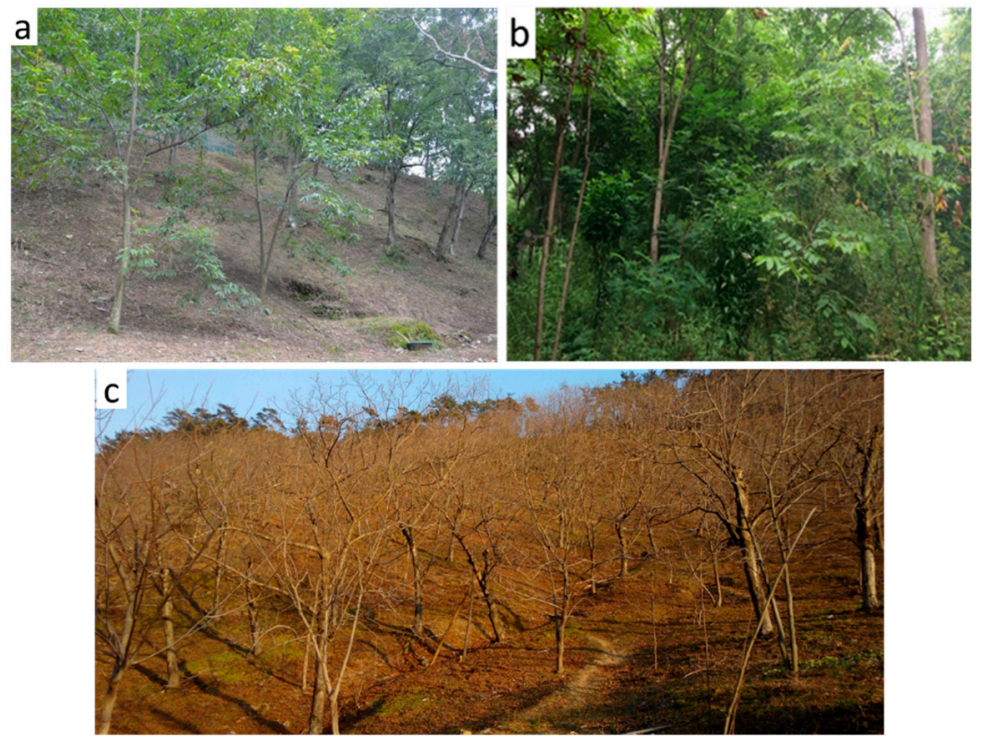

Figure 1. Comparison of stand structure characteristics between (a) hickory plantations-leaf-on; (b) other broadleaf forests-leaf-on; and (c) hickory plantations-leaf-off, highlighting the clear understory in hickory plantations.

The 2013 extreme drought event has resulted in many serious problems such as lack of drinking water, reduced crop yields, forest damage, and human health issues [2-5]. According to the datasets from a local weather station in Daoshi Township, Lin An City, if we consider the days in 2013 when the mean daily temperature was greater than $25^{\circ} \mathrm{C}$ and the daily maximum temperature was greater than $30^{\circ} \mathrm{C}$, the time period between 1 July and 18 August meets this criteria. For this period, we analyzed the mean daily temperature, daily maximum temperature, and rainfall from 2010 to 2015 (see Figures 2 and 3). Overall, the mean daily temperature and daily maximum temperature in 2013 were higher than in other years. In particular, 5-18 August 2013, had high temperatures of 37-41 ${ }^{\circ} \mathrm{C}$ after more than one month of high temperatures with very little rainfall (see Figures $2 b$ and $3 b$ ) and seriously influenced the hickory plantations. At the same time, rainfall in 2013 was significantly less than in other years; that is, only $32.4 \mathrm{~mm}$ of rainfall from 1 July to 18 August compared to more than $198 \mathrm{~mm}$ in the same period in other years (Figure 3b). Due to this drought, about $90 \%$ of the hickory plantations were affected to a certain degree, resulting in forest degradation over a large area, according to a survey by Lin An Forestry Bureau (personal communication). This type of widespread disturbance requires rapidly detecting spatial distribution of drought-induced disturbances.

The repeated acquisition capability of remote sensing data makes it possible to timely detect land-cover change [6]. In particular, the availability of time-series Landsat data at no cost promotes its extensive application for detecting forest disturbances [7-15]. Many techniques and methods, including tasseled cap transform, vegetation indices, and vegetation change tracker (VCT), have been developed to detect forest disturbances [16-22]. For example, based on time-series Landsat data, Huang et al. [11,23] proposed the VCT approach to detect forest disturbance in eastern USA. Kennedy et al. [24] proposed the trajectory-based change detection approach to identify forest disturbance and further proposed the LandTrendr-temporal segmentation algorithms-to automatically detect forest disturbance and restoration [12]. 

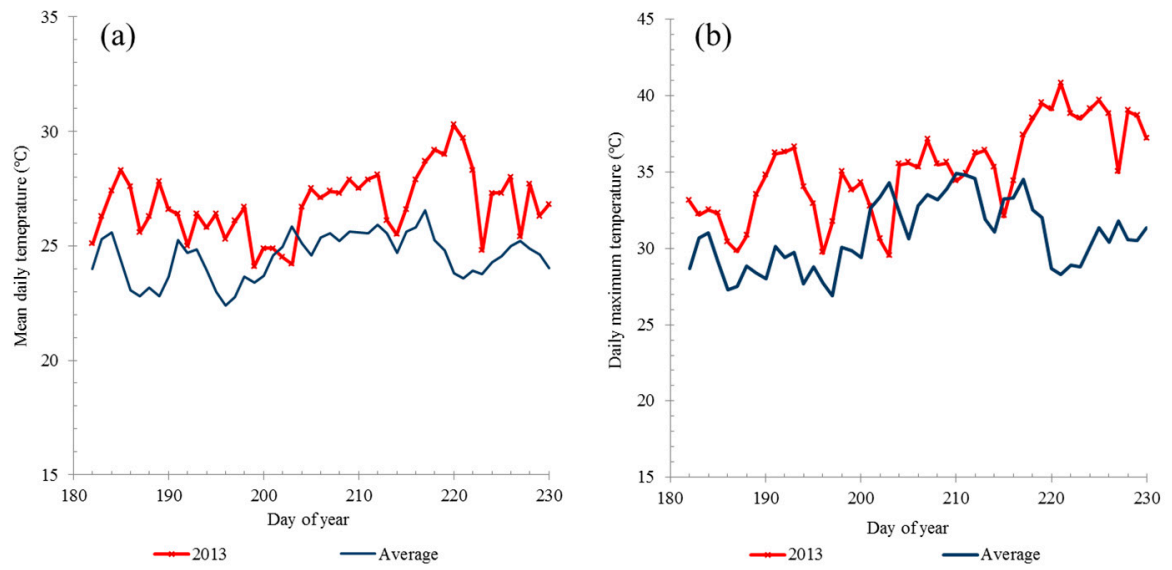

Figure 2. A comparison of mean daily temperatures (a) and daily maximum temperatures (b) from 1 July to 18 August in 2013 and the corresponding averages of the same periods between 2010 and 2015 except 2013, based on data from the weather station at Daoshi Township in the northwestern part of our study area (note: the average values in blue line represent the average of the daily values in 1 July-18 August in the years of 2010, 2011, 2012, 2014, and 2015).

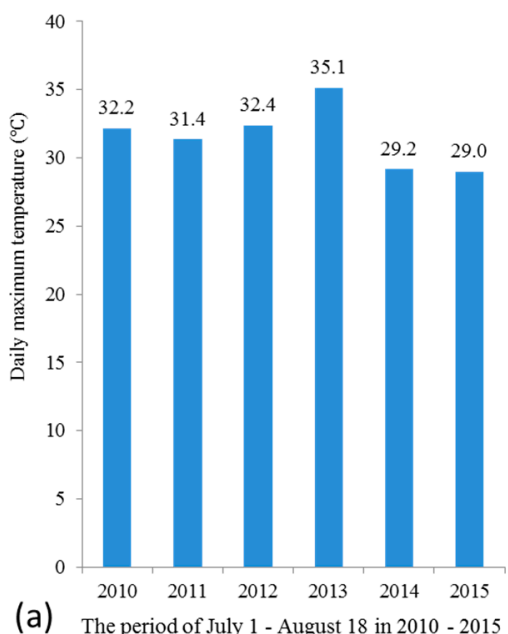

(a) The period of July 1 - August 18 in $2010-2015$

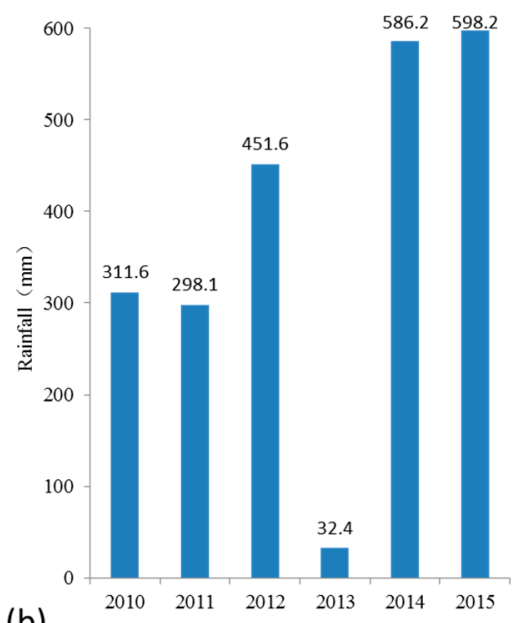

(b) The period of July 1 - August 18 in 2010 - 2015

Figure 3. Mean maximum temperatures (a) and total rainfall amounts (b) during the period of 1 July-18 August from 2010 to 2015, showing the drought event in 2013.

Drought is one of the disturbance factors, and drought-induced disturbance has its own characteristics compared to other kinds of disturbance factors such as forest disease and selective logging. Drought can cause loss of moisture in leaves and canopy, resulting in a change in spectral signatures, especially in red, near-infrared, and shortwave infrared, or change in surface temperature. Therefore, the remote sensing-based approaches for drought-induced disturbance detection are based on the effective use of vegetation indices and/or land surface temperature [16,25-27]. For example, the following three approach categories have been used for detection of drought-induced forest disturbances: (1) vegetation indices, such as Normalized Difference Vegetation Index (NDVI), Enhanced Vegetation Index (EVI), Normalized Difference Water Index (NDWI), Modified Soil Adjust Vegetation Index (MSAVI), and the Perpendicular Drought Index (PDI) [28-32]; (2) surface temperature, such as Temperature Condition Index (TCI) and Normalized Difference Temperature Index (NDTI) [33]; and (3) combination of vegetation index and surface temperature, such as Temperature-Vegetation Drought Index (TVDI) and the Vegetation-Temperature Condition Index (VTCI) [34-38]. Much previous research for drought-induced disturbance detection is based on the examination of time series 
vegetation index data with coarse spatial resolution (e.g., MODIS NDVI), but these approaches cannot effectively detect the disturbance of specific forest types with dispersed distribution and small patch sizes, such as the hickory plantations in this research.

Although many studies have been conducted for detecting drought-induced disturbance, these approaches are influenced to a certain degree by external factors (e.g., soil moisture, topographic factors), data saturation, and insensitivity; thus, small changes in vegetation structure due to a drought event are difficult to detect. The differences in strength and length of a drought event can have considerably different effects on forest disturbance. A short-term drought will not seriously affect forest conditions. Even in the 2013 drought event, its effects varied depending on topography and human activities; thus, it is not enough to just detect whether a disturbance occurred or not. The previously-used pixel-based approaches may not effectively detect a drought-induced forest disturbance. Therefore, this research aimed to develop a new approach to distinguish drought-induced disturbances into different levels and to apply this approach to map spatial distribution of hickory disturbances in a mountainous region.

\section{Study Area}

Lin An, located in the western part of Zhejiang Province and close to Anhui Province (see Figure 4), has a population of 566,700 according to the 2010 census data. In this county, hickory plantations have played an important role in improving economic conditions for local people and government because of its large area distribution and a long history of using hickory nuts [39]. In the past three decades, hickory plantations continuously increased and reached an area of 28,700 ha in Lin An County. As the "capital of hickory in China", Lin An's hickory plantations account for $51.3 \%$ and $46 \%$ of China's hickory nuts production and plantation area, respectively [40]. In this research, the western region of Lin An County, covering 10 townships with an area of approximately $1457 \mathrm{~km}^{2}$, was selected as a study area for exploring the approach to detect hickory disturbances caused by the extreme drought event in July-August 2013.

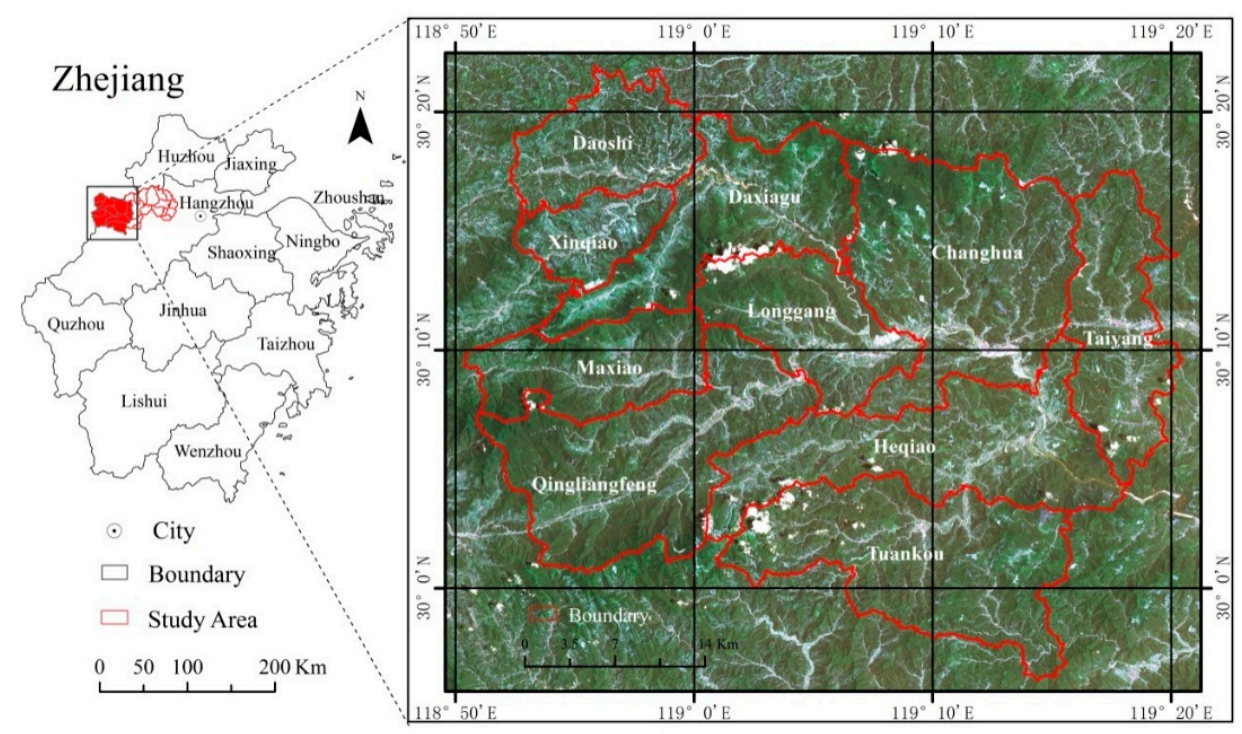

Figure 4. Study area-covering 10 townships in western Lin An County, Zhejiang Province.

Lin An has four distinct seasons-high rainfall in the spring, hot and humid in the summer, mild temperatures in the fall, and cold in the winter. Annual average temperature is $16.4{ }^{\circ} \mathrm{C}$ with the highest temperature in July and the coldest in January. Annual average precipitation is $1614 \mathrm{~mm}$ with June being the rainiest month [41]. Lin An has an undulating terrain with flat terrain in the east and mountainous regions in the west, with elevation ranging from 10 to $1580 \mathrm{~m}$. The major vegetation 
types include coniferous forests (e.g., pines and firs), broadleaf forests (mainly evergreen forest and a limited number of deciduous forests), bamboo forests, and shrubs.

\section{Methods}

\subsection{Data Collection and Preprocessing}

Three Landsat 8 OLI (Operational Land Imager) images in 2013, RapidEye in 2012, and digital elevation model (DEM) data with 30-m spatial resolution were used in this research (Table 1). The Landsat $8 \mathrm{~L} 1 \mathrm{~T}$ product (systematic precision and terrain corrected) has precise geometric accuracy, thus no image-to-image registration among the OLI images is needed. However, DEM data have geometric errors compared with Landsat OLI data. Therefore, 30 GCPs (ground control points) were collected from both DEM and Landsat OLI data for DEM-to-image geometric registration, and a root mean squared error of less than 0.5 pixels was obtained.

Table 1. Datasets used in research.

\begin{tabular}{|c|c|c|c|c|}
\hline Dataset & Acquisition Data & Azimuth & Sun Elev. Angle & Note \\
\hline \multirow{3}{*}{$\begin{array}{l}\text { Landsat } 8 \text { OLI } \\
\text { (path/row:120/39) }\end{array}$} & 10 July 2013 & 105.64 & 68.00 & $\begin{array}{l}\text { This image is the only } \\
\text { cloud-free image available } \\
\text { close to pre-drought event }\end{array}$ \\
\hline & 14 October 2013 & 152.60 & 47.91 & $\begin{array}{l}\text { This image is the only } \\
\text { cloud-free image available } \\
\text { close to post-drought event }\end{array}$ \\
\hline & 1 December 2013 & 158.42 & 34.96 & $\begin{array}{l}\text { The image in leaf-off season is } \\
\text { used to map distribution of } \\
\text { hickory plantations }\end{array}$ \\
\hline RapidEye images & \multicolumn{4}{|c|}{$\begin{array}{l}\text { The RapidEye images in } 2012 \text { were used mainly for selection of more training samples for } \\
\text { urban, water, and agricultural lands }\end{array}$} \\
\hline ASTER GDEM & \multicolumn{4}{|c|}{$\begin{array}{l}\text { These data with } 30-\mathrm{m} \text { spatial resolution were registered into the same coordinate system as } \\
\text { Landsat } 8 \text { OLI data and are used to conduct topographic correction of Landsat imagery. }\end{array}$} \\
\hline Field surveys & \multicolumn{4}{|c|}{$\begin{array}{l}\text { Fieldwork was conducted in June 2013-August 2014. A total number of } 84 \text { vegetation samples } \\
\text { were collected, including } 20 \text { for hickory plantations, } 30 \text { for evergreen forests, } 20 \text { for other } \\
\text { deciduous broadleaf forests, and } 14 \text { for shrubs. }\end{array}$} \\
\hline
\end{tabular}

Since the extreme drought event occurred between early July and late August 2013, the best image acquisition dates for this drought-induced disturbance detection should be between late June and late August or early September. In this time period, hickory plantations are in the middle of their growing season, and their stand structures are stable if no disturbance has occurred. However, due to cloud cover, Landsat 8 OLI imagery on 10 July is the only cloud-free image available close to the beginning of the drought event, and Landsat 8 OLI imagery on 14 October is the only available data close to the end of the drought event. Therefore, both July and October Landsat images were used to detect forest disturbances. Since hickory is a deciduous forest and use of leaf-on and leaf-off images can improve the extraction of hickory plantations, July (leaf-on) and December (leaf-off) Landsat OLI images were used to extract hickory distributions.

The Landsat 8 OLI Digital Number (DN) was converted to TOA (Top of Atmosphere) reflectance [42]. The Dark Object Subtraction approach was then used to convert TOA to surface reflectance [43]. Since topographic factors seriously influence land surface reflectance in mountainous regions [44], topographic correction is required for the Landsat imagery before the data can be used for further quantitative analysis such as vegetation classification. In this research, the C-correction approach was used to conduct topographic correction $[45,46]$ considering the influence of the relatively low sun elevation angle on the December Landsat imagery.

Fieldwork was conducted in 2013 and 2014. In June 2013, we conducted field surveys to identify vegetation types (e.g., pine, Chinese firs, broadleaf forests, hickory plantations, bamboo forests, shrubs, 
crop fields). A GPS device was used to collect the coordinates of each sample plot. The field survey data were linked to Landsat OLI imagery to generate training samples. We used RapidEye imagery to collect training samples in Lin An mainly for urban, water, and agricultural lands. In early September 2013, our collaborators provided us field survey data and photos for examining the forest damages caused by the July-August drought. Large areas of dead trees were not found in the hickory plantations during the field surveys. However, individual dead trees were dispersed across the study area in locations where soil characteristics limited water holding capacity. According to the field survey, four disturbance levels—non-disturbance, light, medium, and severe (see Figure 5)—are defined as follows:

(1) Non-disturbance means that the hickory trees grew normally without influence from this drought event (Figure 5a). This situation is mainly located at lower elevations of mountainous regions or in valleys with good soil conditions and moisture.

(2) Light disturbance means that some leaves became yellow due to moisture loss in the hickory leaves, but they would be restored in a short time if sufficient moisture were available (Figure $5 b$ ). We define the light level for those sites where at least half of the hickory trees in a hectare had yellow leaves in early September (just after the drought event).

(3) Medium disturbance means that some leaves and branches in the upper part of a tree died but most of the leaves and branches in the lower part of a tree were still alive (see Figure $5 \mathrm{c}$ ). We define the medium level for those sites where at least half of the hickory trees in a hectare had dead leaves in early September (just after the drought event).

(4) Severe disturbance means that the leaves became red and died due to moisture loss caused by the drought event (see Figure 5d). This situation often occurred in the areas with very poor soil conditions. During the field survey, we did not find this category because only a few trees were dead in a hectare due to the drought event.
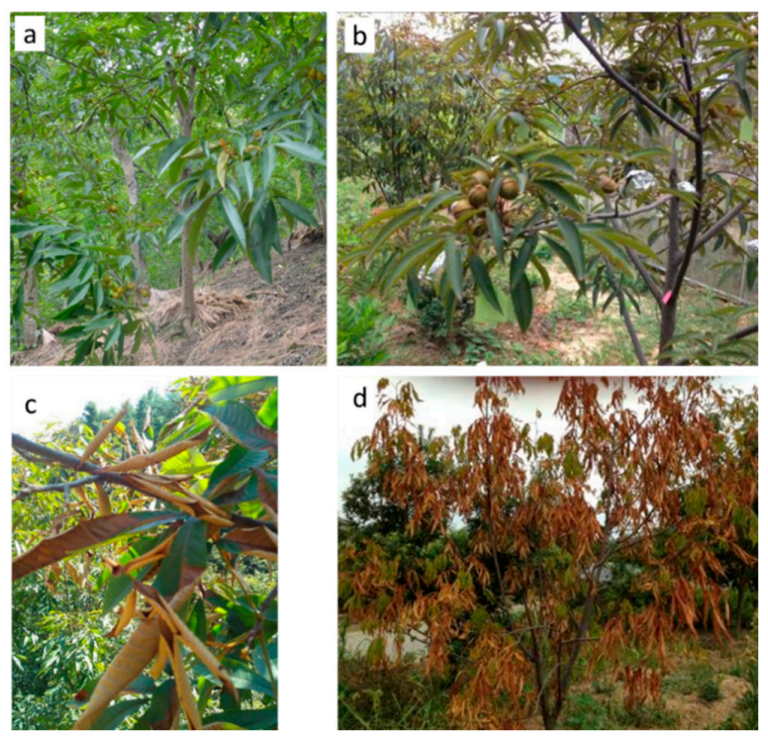

Figure 5. Four levels of hickory disturbances resulting from the July-August 2013 drought event (a) non-disturbance; (b) light; (c) medium and (d) severe.

In August 2014, we did another field survey in this study area trying to identify more sites of different disturbance levels based on the definitions given above. Unfortunately, we could not clearly identify the disturbed regions because the trees had restored after one year. We further interviewed some hickory plantation owners about the impacts of the 2013 drought event. We have the impression that the 2013 extreme drought event indeed influenced hickory damage to a certain degree and 
seriously affected the 2013 and 2014 hickory nut production and quality, but completely dead trees were limited. Although these qualitative descriptions cannot be effectively used in this research, it indeed indicated the negative effects of this drought event on hickory production.

\subsection{Mapping Hickory Plantation Distribution}

Hickory belongs to a deciduous broadleaf forest. Its spectral signature is similar to other broadleaf forests (see Figure 6), resulting in difficulty in distinguishing them using remote sensing spectral signatures. However the hickory plantation has a different stand structure compared to other broadleaf forests (see Figure 1): that is, a hickory plantation has a relatively simple stand structure due to its single tree species composition and no or limited understory vegetation caused by human-induced intensive management for the sake of harvesting hickory nuts. Based on this unique feature, Figure 7 illustrates the framework of mapping hickory plantations using two Landsat 8 OLI data from July and December 2013. The major steps include (1) separate deciduous and evergreen forests using the NDVI image differencing approach; (2) develop fraction images using linear spectral mixture analysis (LSMA) and further generate new indices from these fraction images; (3) separate hickory plantations from other deciduous forests using the thresholding approach based on the newly developed index from the fraction images; and (4) evaluate hickory plantation results using field survey data.

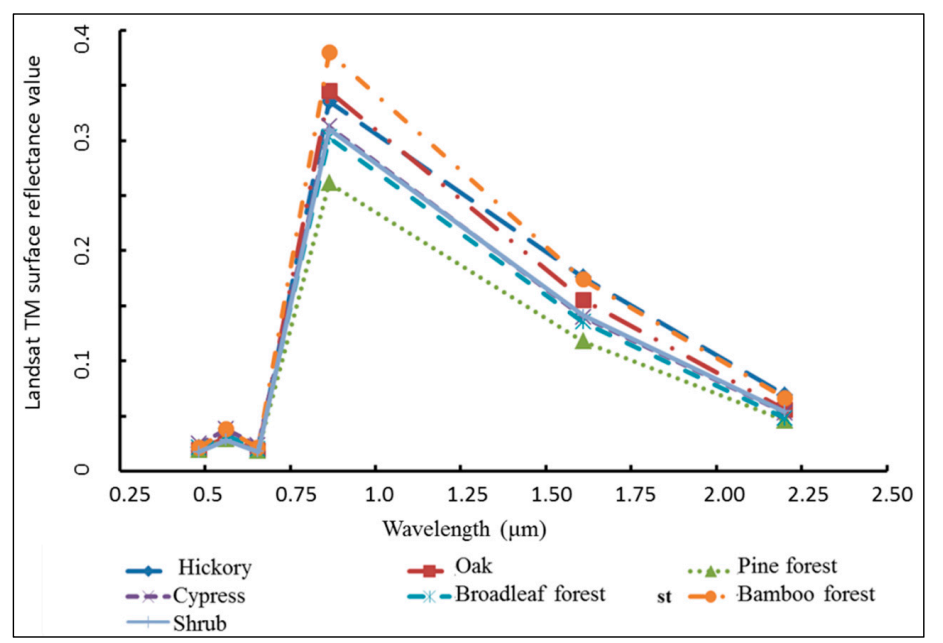

Figure 6. Spectral signatures of major vegetation types in this study area.

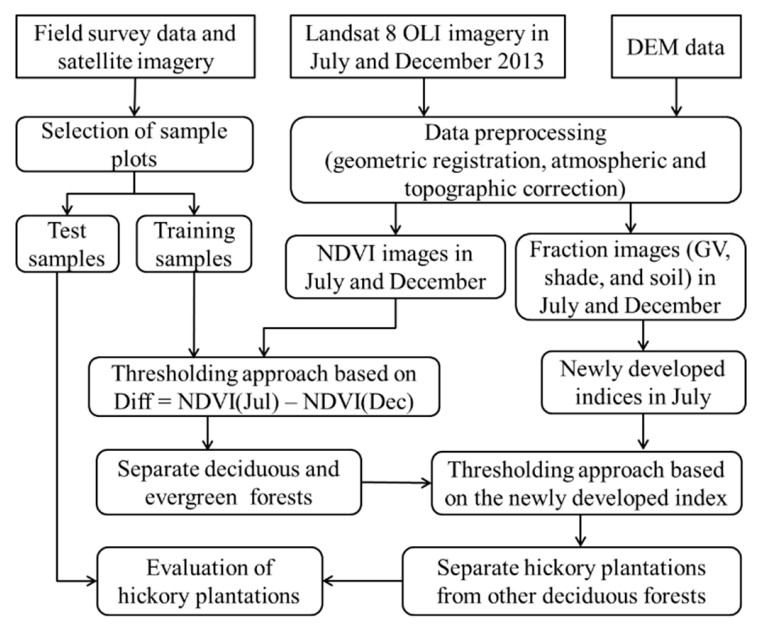

Figure 7. Framework of mapping hickory distribution using Landsat 8 OLI imagery in summer and winter seasons. 
Since hickory is a deciduous tree species, use of leaf-on and leaf-off season images can easily separate deciduous forest from evergreen forests. Here we used NDVI image differencing between Landsat images in July and December to classify vegetation into deciduous and evergreen forests.

Previous research has shown that the fractions developed from Landsat imagery using LSMA are good variables for examining forest stand structure [47]. For example, a forest site can be assumed to be a combination of green vegetation (GV), shade (SH), and soil (SO) components. GV reflects the vegetation density at horizontal scale, $\mathrm{SH}$ represents the vertical stand structure, and SO represents non-photosynthetic vegetation information such as stems and branches, in addition to soils under the forest canopy [47]. In the LSMA approach, selection of good-quality endmembers is one of the critical steps. Although image- or reference-based approaches [47] can be used, the image-based approaches are commonly used for selection of endmembers. In order to identify high-quality endmembers, Landsat multispectral bands were transformed into a new dataset using image transform algorithms, such as principal component analysis and minimum noise fraction [48,49]. In this research, three endmembers- $\mathrm{GV}, \mathrm{SH}$, and $\mathrm{SO}$ - were selected from the first three components, which were transformed from Landsat OLI multispectral imagery using minimum noise fraction. A constrained least squares solution was then used to unmix the Landsat OLI multispectral imagery into three fraction images. This approach was used to develop fraction images for the three dates of Landsat OLI data separately (i.e., July, October, and December 2013). A detailed description of the LSMA approach is available in previous literature (e.g., $[47,48])$.

Since three fraction variables represent different forest stand characteristics, the ratio of these factions may further enhance the difference in stand structures between hickory plantations and other broadleaf forests. Therefore, three new indices, called vegetation-soil (VSO) index, vegetation-shade (VSH) index, and normalized multi-fractions (NMF) index were proposed in this research:

$$
\begin{gathered}
\mathrm{VSO}=\frac{\mathbf{G V}-\mathrm{SO}}{\mathrm{GV}+\mathrm{SO}} \\
\mathrm{VSH}=\frac{\mathbf{G V}-\mathrm{SH}}{\mathbf{G V}+\mathbf{S H}} \\
\mathrm{NMF}=\frac{\mathbf{G V}+\mathbf{S H}-\mathbf{S O}}{\mathbf{G V}+\mathbf{S H}+\mathbf{S O}}
\end{gathered}
$$

where $\mathrm{GV}, \mathrm{SH}$, and $\mathrm{SO}$ represent green vegetation, shade, and soil fractions, respectively, which were developed from Landsat multispectral imagery using the LSMA approach. A comparison of three fraction (i.e., GV, SH, and SO) images and newly proposed indices (i.e., VSO, VSH, and NMF) was conducted based on field survey data to identify the best one for separating hickory from deciduous forests, as shown in Figure 8. The NMF was finally selected to map hickory plantation distribution using the thresholding-based approach, which was based on the July and December 2013 Landsat 8 OLI images [50]. Figure 9 illustrates the hickory plantation distribution in this study area using the NMF-based approach. A detailed description of this approach is provided in Xi et al. [50]. Here we directly used the hickory distribution result to further examine spatial distribution of hickory disturbances.

Accuracy assessment was conducted using 150 sample plots, including 55 samples of hickory plantations and 95 other land covers, which were collected using a stratified sampling technique, according to field survey and visual interpretation of RapidEye imagery. The result indicated that an overall accuracy of $88.8 \%$ and kappa efficiency of 0.76 were obtained. The producer's and user's accuracies of $82.8 \%$ and $87.3 \%$, respectively, for the hickory forest were achieved. 


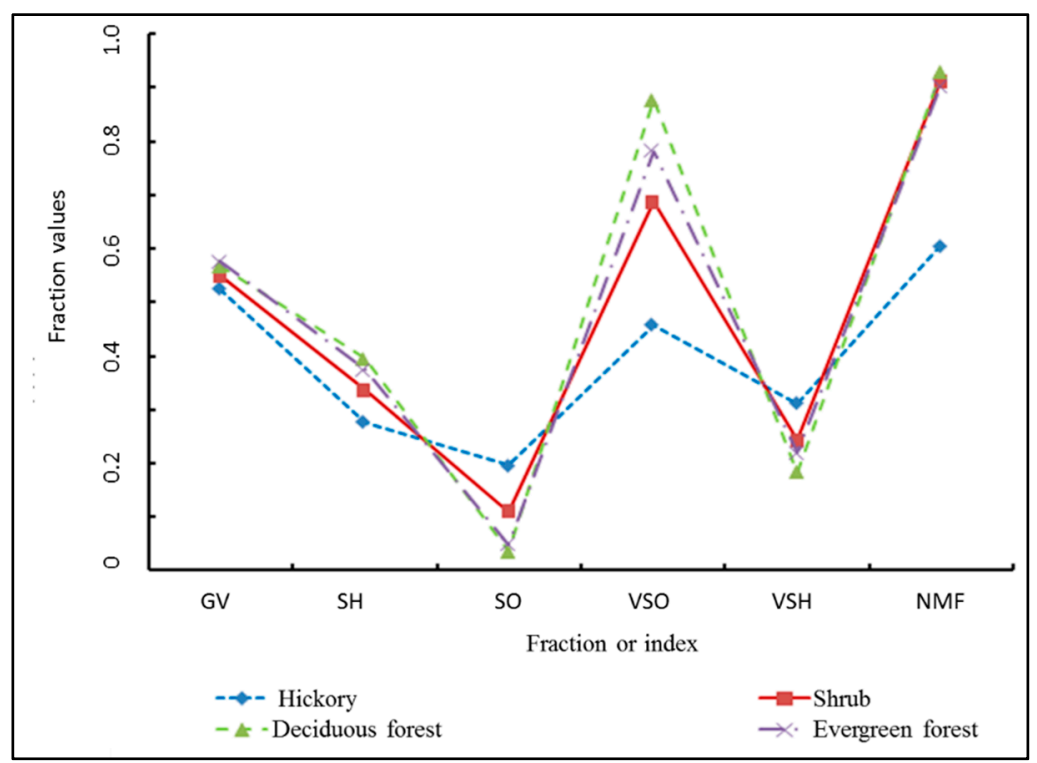

Figure 8. A comparison of fractional variables and newly proposed variables.
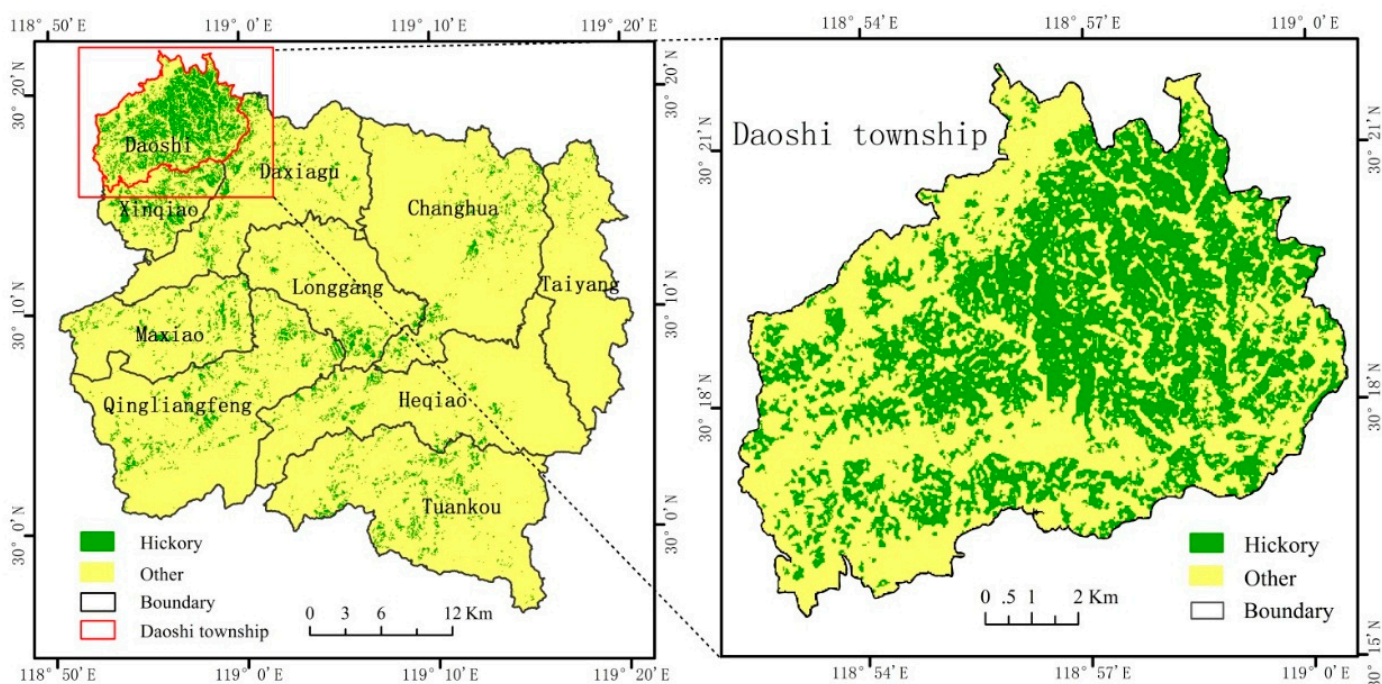

Figure 9. Spatial distribution of hickory plantations using the Landsat 8 OLI images in summer and winter seasons.

\subsection{Detecting Drought-Induced Disturbances of Hickory Plantations}

Figure 10 illustrates the framework of detecting hickory disturbances caused by drought in July-August 2013 using Landsat 8 OLI images which were acquired in July and October 2013. The major steps include (1) map hickory plantation distribution using the leaf-on and leaf-off imagery (i.e., July and December imagery), as described in Section 3.2; (2) develop fraction images from the July and October Landsat multispectral imagery using the LSMA approach and produce new indices from the fractional images; and (3) determine thresholds based on the selected variable and map spatial distribution of different disturbances. 


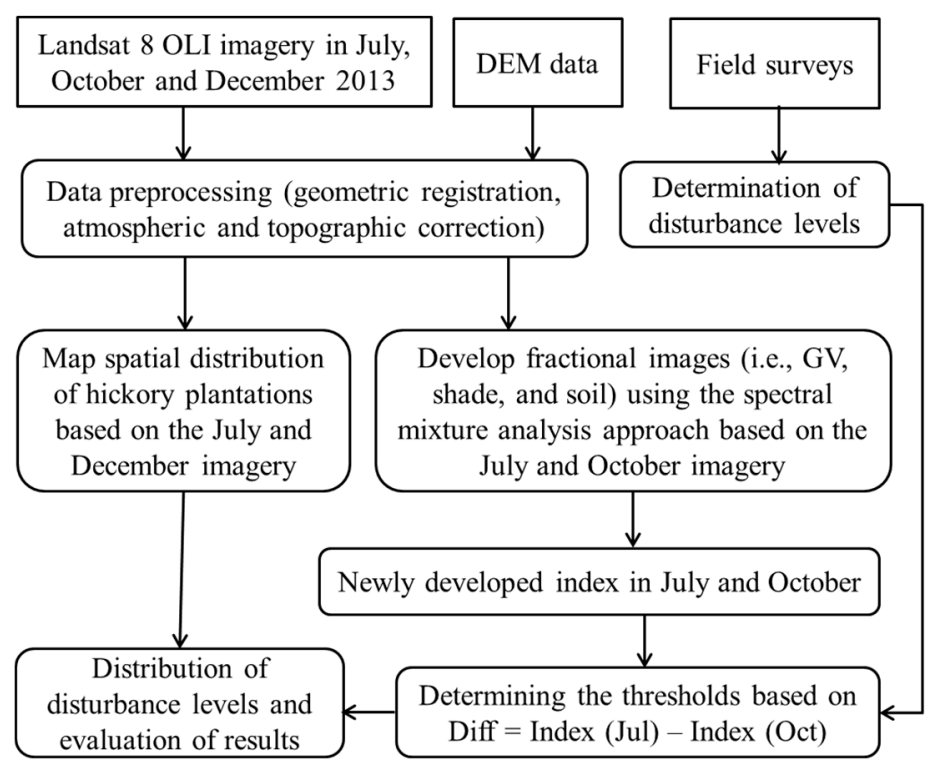

Figure 10. Framework of detecting hickory disturbances using Landsat 8 OLI imagery.

Drought causes a loss of moisture in a forest site. As moisture decreases, the shade fraction decreases, but soil fraction increases. Therefore, the ratio of GV to soil fraction $\left(\mathrm{R}_{\mathrm{SO}}\right)$ and the ratio of GV to the shade fraction $\left(R_{S h}\right)$ were proposed to examine the potential forest disturbance caused by drought. Meanwhile, three other vegetation indices showing sensitivity to vegetation status were examined to compare the newly developed indices and commonly used indices [28,51,52]:

$$
\begin{gathered}
R_{\mathrm{SO}}=\mathrm{GV} / \mathrm{SO} \\
R_{\mathrm{Sh}}=\mathrm{GV} / \mathrm{SH} \\
N D V I=\frac{\rho_{\mathrm{NIR}}-\rho_{\mathrm{RED}}}{\rho_{\mathrm{NIR}}+\rho_{\mathrm{RED}}} \\
E V I=2.5 \times \frac{\rho_{\mathrm{NIR}}-\rho_{\mathrm{RED}}}{\rho_{\mathrm{NIR}}+6.0 \rho_{\mathrm{RED}}-7.5 \rho_{\mathrm{BLUE}}+1} \\
M S A V I=\frac{\left(2 \rho_{\mathrm{NIR}}+1\right)-\sqrt{\left(2 \rho_{\mathrm{NIR}}+1\right)^{2}-8\left(\rho_{\mathrm{NIR}}-\rho_{\mathrm{RED}}\right)}}{2}
\end{gathered}
$$

where $R_{S O}$ and $R_{S H}$ represent the ratios of GV to the soil fraction and GV to the shade fraction, respectively; GV, $\mathrm{SH}$, and $\mathrm{SO}$, respectively, represent green vegetation, shade, and soil fraction images that were developed from Landsat imagery using the LSMA approach; $\rho_{\mathrm{NIR}}, \rho_{\mathrm{RED}}$, and $\rho_{\text {BLUE }}$ respectively represent land surface reflectance at near-infrared, red, and blue wavelengths in the Landsat 8 OLI imagery. NDVI, EVI, and MSAVI represent normalized difference vegetation index, enhanced vegetation index, and modified soil adjust vegetation index, respectively.

Based on field survey data, we found that GV value decreased, but the soil fraction increased after drought because of withered or dead leaves. However, the forest stand structure did not change significantly; thus, the shade fraction remained stable when the drought effect was not serious. Since drought leads to increased soil and decreased GV fractions, the ratio of GV to soil fractions considerably enlarges the ranges from high values before drought to low values after drought. Therefore, the $R_{\mathrm{SO}}$ differencing between before and after drought is used to separate these four disturbance levels using a thresholding-based approach. In general, the threshold values can be determined with two approaches: (1) manual trial-and-error procedure and (2) statistical measures [6]. In this research, the threshold values were determined with a combined use of statistic measures (i.e., mean and standard deviation) 
and trial-and-error adjustment based on field survey data, that is, an initial threshold was selected for each disturbance level according to mean \pm 2.5 standard deviation, then the thresholds were further adjusted using the trial-and-error approach based on the analysis of field survey data.

Accuracy assessment is an important part in a change detection procedure [6]. The error matrix approach that is often used for classification accuracy assessment [53,54] can also be used for change detection accuracy assessment. However, collection of reference data is very difficult because it requires collecting them from the change detection period [6]. This is especially a challenge for forest disturbance evaluation because the disturbance will be repaired in a certain time period through forest growth if the reference data are not collected on time. In this research, we do not have sufficient reference data to conduct a quantitative evaluation of the hickory disturbance result, but we interviewed some hickory plantation owners during August 2014 and examined the results with them for qualitative evaluation.

\section{Results}

Based on sample plots of hickory plantations, Figure 11 provides a comparison of selected indices before and after drought, indicating that individual fractional images (GV, $\mathrm{SH}$, and $\mathrm{SO}$ ) and three vegetation indices (NDVI, EVI, and MSAVI) have small changes. However, the ratio of GV to soil fraction, $\mathrm{R}_{\mathrm{SO}}$, considerably enlarges the range of change from a high value before drought to a low value after drought. Thus, this ratio is a good variable for examining the hickory disturbances caused by this drought event.

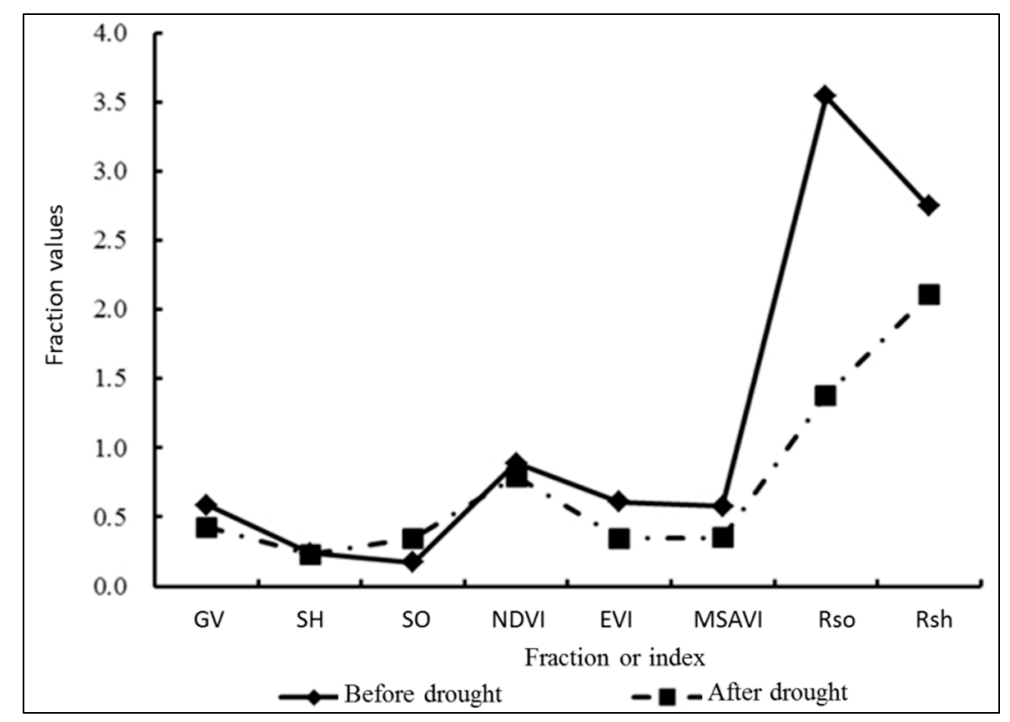

Figure 11. A comparison of selected variables before and after the 2013 drought event.

Based on field survey data (see Table 1) and the definitions of four disturbance levels, their thresholds were determined and are summarized in Table 2. The area proportion of each level for all hickory plantations in the study area was also calculated, indicating that the majority of the hickory plantations are at non- or light-disturbance level and are mainly located at the foot of mountains or in valleys with good soil conditions. Medium disturbance level is limited, accounting for only $8.7 \%$ and mainly located in such sites as mountain ridges with poor soil conditions, while severe disturbance level does not have an obvious spatial pattern and is thinly dispersed on some mountain ridges. Figure 12 provides the spatial distribution of hickory disturbances, indicating that most hickory plantations with non- or light-disturbance level are in Daoshi Township. 

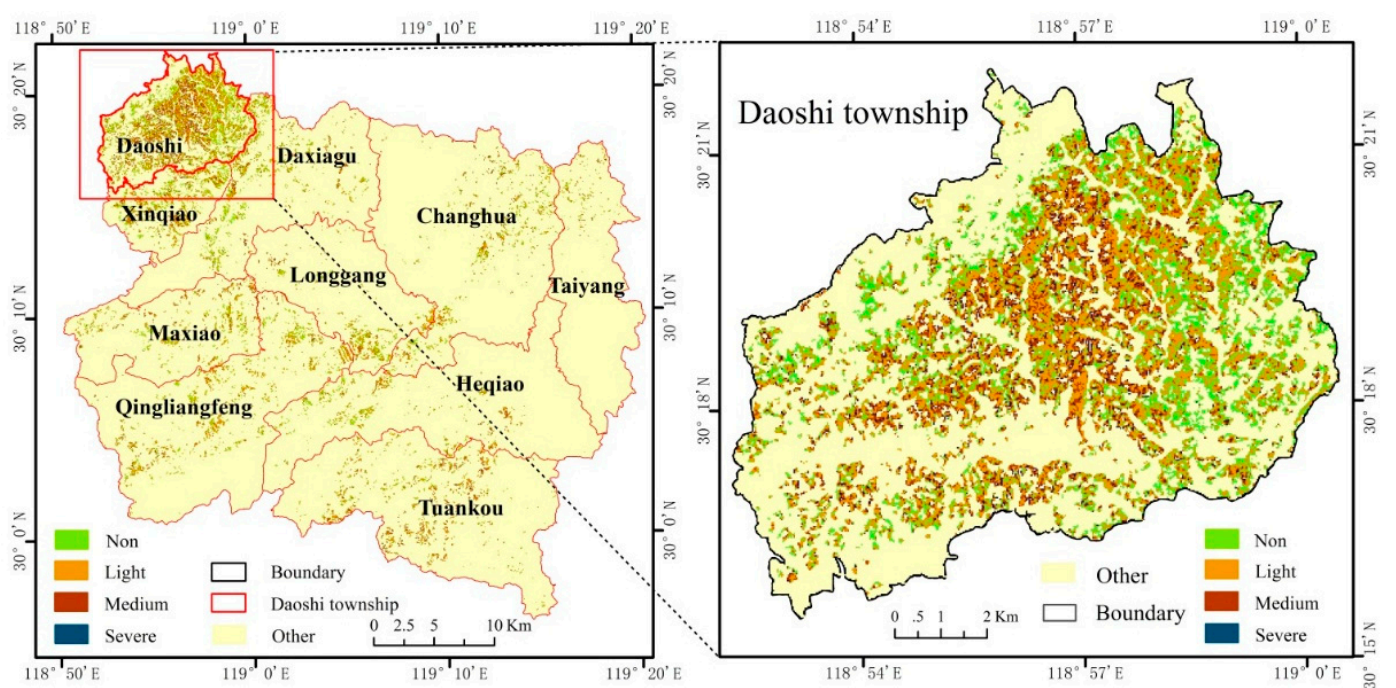

Figure 12. Spatial distribution of drought-induced disturbance levels derived using the $\mathrm{R}_{\mathrm{SO}}$-based approach.

Table 2. A summary of the identified thresholds for defined disturbance levels and their proportions to total hickory plantation area.

\begin{tabular}{|c|c|c|c|}
\hline $\begin{array}{l}\text { Disturbance } \\
\text { Levels }\end{array}$ & Threshold & $\%$ & Spatial Patterns \\
\hline Non & $<1.88$ & 29.7 & $\begin{array}{l}\text { Mainly located at the foot of mountains and in } \\
\text { valleys with good soil conditions. }\end{array}$ \\
\hline Light & $1.89-3.10$ & 58.8 & $\begin{array}{l}\text { Mainly distributed in Daoshi Township where } \\
\text { hickory plantations account for a large } \\
\text { proportion of their mountainous areas and } \\
\text { plantation owners had intensive management, } \\
\text { including irrigation during the drought period }\end{array}$ \\
\hline Medium & $3.11-4.07$ & 8.7 & $\begin{array}{l}\text { Mainly located at mountain ridges with poor } \\
\text { soil conditions }\end{array}$ \\
\hline Severe & $>4.08$ & 2.7 & $\begin{array}{l}\text { Dispersed in some mountain ridges without } \\
\text { obvious spatial patterns }\end{array}$ \\
\hline
\end{tabular}

Thresholds were determined from field survey data; \% represents the proportion of each disturbance level in the total hickory plantation area.

Despite the light and medium disturbances detected across the study area, the drought event indeed influenced the hickory nut production and quality in 2013 and 2014 according to our interviews with the hickory plantation owners. Although no quantitative accuracy assessment for the disturbance detection result was conducted due to insufficient field survey data, we are confident with the spatial patterns of the detected disturbances based on the interview results.

\section{Discussion}

The majority of the change detection techniques, such as vegetation indices and image differencing, are designed for land-cover conversion; that is, a complete change from one type to another such as from forest to cropland [6,55]. However, the traditional change detection techniques cannot easily detect forest modification, such as the drought-induced forest disturbances in this research [56]. Here we provide an alternative to detect forest disturbances by examining the change in ratios of GV to soil fractions before and after drought based on multi-temporal Landsat imagery. This proposed approach is effective in detecting hickory distribution and may be used for detecting other forest disturbances, such as forest disease and selective logging. 


\subsection{Selection of Suitable Image Acquisition Dates for Forest Disturbance Detection}

Hickory is a deciduous tree species, meaning that the leaves are in full development from May to October, then gradually become yellow in late fall, and finally fall in winter. This characteristic requires selection of a suitable season for detecting hickory disturbance. It is critical to use before-event and after-event images in the same growing season to reduce the impacts of vegetation growing/fading seasons on the detection performance. For the hickory plantations in the same growing season, such as in the months of May to September, the forest stand structure is stable if no disturbance occurs. In this situation, the fraction images (e.g., GV, shade, soil) are stable. However, if one image is from a non-growing season or in a late- or early growing season when leaves have fallen or not fully developed, the canopy cover and soil may considerably affect the composition of GV, shade, and soil components. In this case, the proposed approach using the ratio of GV to soil fraction is not suitable for detecting forest disturbances because spurious changes caused by different seasons affect the detection performance. Therefore, it is important to select the Landsat images in the mid-growing season to detect forest disturbances.

Although Landsat imagery is often used for detection of forest disturbances, its 16-day revisit and cloud cover problem, especially in tropical and subtropical regions, is a critical constraint. In recent years, different sensors with high temporal and spatial resolutions, such as RapidEye and Pleiades, have become available, providing new opportunities to accurately and timely detect forest disturbances [6]. Since LSMA can effectively unmix multispectral imagery into fractional images if endmembers can be properly selected [57], the fractional images developed from different sensors' multispectral imagery can be reliable. Since radar data, especially the long-wave radar such as ALOS PALSAR L-band, can penetrate the forest canopy to a certain depth for capturing more information about forest structure and understory, a combination of radar and optical sensor data may provide better performance in forest disturbance detection [58-61]. Although the spatial resolution in MODIS vegetation indices (e.g., NDVI, EVI) is too coarse to detect disturbances in specific forest types with relatively small patch sizes, such as hickory plantations in this research, its unique characteristics in time series vegetation indices indeed provided important disturbance information in a large area [29,32,37]. Integration of time series MODIS NDVI (or EVI) and Landsat images may improve forest disturbance accuracy. However, use of different sensor data produces a challenge in effectively detecting forest disturbances, requiring more research to develop suitable technologies [62].

\subsection{Determination of Disturbance Levels and Evaluation of Disturbance Results}

Quantitative definition of disturbances is often difficult because disturbance is a continuous stage without an obvious boundary [63]. In this research, the hickory disturbances caused by extreme drought in 2013 were grouped into four disturbance levels: non-disturbance, light, medium, and severe, based on field survey data. The definition of each level is still subjective, depending on the decisions of how many levels and what thresholds to use, and the characteristics of the study area.

In this research, the field survey date and remote sensing acquisition date did not fit well to the time of the drought event. Thus, the results from remote sensing data may not accurately represent the true disturbance levels due to the time differences between data collection and the disturbance and forest restoration. This disturbance may be spurious due to the hickory nut harvest in mid-September and leaves' color change due to decreased temperature in the late growing season. The slight difference in growing seasons (mid-growing season in July and late growing season in October) makes determination of thresholds difficult. In theory, the threshold for non-disturbance forest should be close to zero, but a value larger than zero can be attributed to the impacts of the slightly different growing seasons and/or to the error of unmixing Landsat multispectral images separately. This difference also makes evaluation of disturbance results difficult if ground-truth data are not collected at the right times, because the natural growth of vegetation will restore its forest stand structure and conceal its past disturbance. 


\subsection{Development of Proper Algorithms for Specific Forest Disturbance}

Previous research has indicated that forest disturbances can be detected by examining changes of vegetation indices $[17,29,32,37]$. These pixel-based approaches may be successful for detecting forest disturbances with large areas and having severe disturbances, but may not be effective for detecting drought-induced forest disturbances because of its small change in forest stand structure or canopy moisture. In this research, we proposed a subpixel approach, which is based on development of fractional images from Landsat multispectral imagery and the use of the ratio of GV to soil fractions to further enlarge the difference between stand structures. This proposed approach can effectively detect the small change in forest stand structures. This advantage is especially valuable for detecting the disturbances caused by drought, forest disease, and selective logging that only result in small changes in forest stand structure. Additionally, this proposed approach provides the potential to detect forest disturbances in small patch sizes that traditional vegetation indices-based approaches at pixel scale do not have this capability.

Drought-induced forest disturbance is often related to topography and soil conditions. For example, the areas with steep slopes often have high risk of soil erosion if forest cover is not dense enough; soil conditions such as soil type and depth can influence the soil's water holding capacity; topography can affect sun illumination, moisture, soil type and, thus, result in different vegetation species distribution and composition. Therefore, more research is needed in the future to develop approaches to incorporate soil and DEM into remote sensing data for more effectively detecting forest disturbances.

\section{Conclusions}

This research proposed a new approach to detect forest disturbances, using hickory disturbances caused by extreme drought in 2013 as an example. Four disturbance levels were defined: non-disturbance, light, medium, and severe. The ratio of GV to soil fraction images was developed from multitemporal Landsat imagery using the LSMA approach and used to map spatial distribution of hickory disturbance levels. This research indicates the value of using the LSMA approach to produce fraction images representing the forest stand structure and the ratio of GV to soil fractions to effectively detect forest disturbances by enlarging the difference between forest structure features before and after drought events. However, caution should be taken in setting and measuring the levels of disturbance and in selection of image acquisition dates. This proposed approach may be used to examine other kinds of disturbances, such as forest disease and selective logging, in other forest types such as bamboo forests. More research is needed in the future to develop approaches to incorporate ancillary data, such as DEM and soils into remote sensing data for better detecting forest disturbance.

Acknowledgments: This research is financially supported by Zhejiang Provincial Natural Science Foundation (LZ15C160001) and Zhejiang Agriculture and Forestry University's Research and Development Fund for the talent startup project (2013FR052). The authors would like to thank Longwei Li for his support in data organization and Jianqin Huang for his support in data collection of hickory disturbances.

Author Contributions: Zhenyuan Xi conducted field data collection, image processing, and resultant analysis. Dengsheng Lu designed the research procedure, conducted resultant analysis, and wrote manuscript. Lijuan Liu and Hongli Ge provided technical support on image processing and field data collection.

Conflicts of Interest: The authors declare no conflict of interest.

\section{References}

1. Huang, J.Q.; Lu, D.; Li, J.; Wu, J.S.; Chen, S.Q.; Zhao, W.M.; Ge, H.L.; Huang, X.Z.; Yan, X.J. Integration of remote sensing and GIS for evaluating soil erosion risk in Northwestern Zhejiang, China. Photogramm. Eng. Remote Sens. 2012, 78, 935-946. [CrossRef]

2. Drought, Heatwaves Affect Tea Plantations in East China. Available online: http://www.globaltimes.cn/ content/804594.shtml (accessed on 21 February 2106). 
3. Mullen, J. Heat Wave Kills People, Crops, Fish, and Hopes in China. Available online: http:/ / www.desdemonadespair.net/2013/08/heat-wave-kills-people-crops-fish-and.html (accessed on 21 February 2016).

4. Zhang, L.S.; Xue, J.J.; Wang, W.G.; Sun, J. Comparative analysis of extreme high temperature weather in the summers of 2013 and 2003. Atmos. Ocean. Sci. Lett. 2014, 7, 132-136.

5. Yuan, W.P.; Cai, W.W.; Chen, Y.; Liu, S.G.; Dong, W.J.; Zhang, H.C.; Yu, G.R.; Chen, Z.Q.; He, H.L.; Guo, W.D.; et al. Severe summer heatwave and drought strongly reduced carbon uptake in Southern China. Sci. Rep. 2016, 18813. [CrossRef] [PubMed]

6. Lu, D.S.; Li, G.Y.; Moran, E. Current situation and needs of change detection techniques. Int. J. Image Data Fusion 2014, 5, 13-38. [CrossRef]

7. Healey, S.P.; Cohen, W.B.; Yang, Z.; Krankina, O.N. Comparison of tasseled Cap-based Landsat data structures for use in forest disturbance detection. Remote Sens. Environ. 2005, 97, 301-310. [CrossRef]

8. Jin, S.; Sader, S.A. Comparison of time series tasseled cap wetness and the normalized difference moisture index in detecting forest disturbances. Remote Sens. Environ. 2005, 94, 364-372. [CrossRef]

9. Masek, J.G.; Huang, C.Q.; Wolfe, R.; Cohen, W.; Hall, F.; Kutler, J.; Nelson, P. North American forest disturbance mapped from a decadal Landsat record. Remote Sens. Environ. 2008, 112, 2914-2926. [CrossRef]

10. Cohen, W.B.; Yang, Z.Q.; Kennedy, R. Detecting trends in forest disturbance and recovery using yearly Landsat time series: 2. TimeSync-Tools for calibration and validation. Remote Sens. Environ. 2010, 114, 2911-2924. [CrossRef]

11. Huang, C.Q.; Goward, S.N.; Masek, J.G.; Thomas, N.; Zhu, Z.L.; Vogelmann, J.E. An automated approach for reconstructing recent forest disturbance history using dense Landsat time series stacks. Remote Sens. Environ. 2010, 114, 183-198. [CrossRef]

12. Kennedy, R.E.; Yang, Z.Q.; Cohen, W.B. Detecting trends in forest disturbance and recovery using yearly Landsat time series: 1. LandTrendr-Temporal segmentation algorithms. Remote Sens. Environ. 2010, 114, 2897-2910. [CrossRef]

13. Thomas, N.E.; Huang, C.Q.; Goward, S.N.; Powell, S.; Rishmawi, K.; Schleeweis, K.; Hinds, A. Validation of North American forest disturbance dynamics derived from Landsat time series stacks. Remote Sens. Environ. 2011, 115, 19-32. [CrossRef]

14. Zhu, Z.; Woodcock, C.E.; Olofsson, P. Continuous monitoring of forest disturbance using all available Landsat imagery. Remote Sens. Environ. 2012, 122, 75-91. [CrossRef]

15. Masek, J.G.; Goward, S.N.; Kennedy, R.E.; Cohen, W.B.; Moisen, G.G.; Schleeweis, K.; Huang, C. United States forest disturbance trends observed using Landsat time series. Ecosystems 2013, 16, 1087-1104. [CrossRef]

16. Richard, R.; Heim, J.R. A review of twentieth-century drought indices used in the United States. Am. Meteorol. Soc. 2002, 83, 1149-1165.

17. Coops, N.C.; Wulder, M.A.; Iwanicka, D. Large area monitoring with a MODIS-based Disturbance Index (DI) sensitive to annual and seasonal variations. Remote Sens. Environ. 2009, 113, 1250-1261. [CrossRef]

18. Hilker, T.; Wulder, M.A.; Coops, N.C.; Linke, J.; McDermid, G.; Masek, J.G.; Gao, F.; White, J.C. A new data fusion model for high spatial- and temporal-resolution mapping of forest disturbance based on Landsat and MODIS. Remote Sens. Environ. 2009, 113, 1613-1627. [CrossRef]

19. Kennedy, R.E.; Yang, Z.; Cohen, W.B.; Pfaff, E.; Braaten, J.; Nelson, P. Spatial and temporal patterns of forest disturbance and regrowth within the area of the Northwest Forest Plan. Remote Sens. Environ. 2012, 122, 117-133. [CrossRef]

20. Loboda, T.V.; Zhang, Z.; O’Neal, K.J.; Sun, G.; Csiszar, I.A.; Shugart, H.H.; Sherman, N.J. Reconstructing disturbance history using satellite-based assessment of the distribution of land cover in the Russian Far East. Remote Sens. Environ. 2012, 118, 241-248. [CrossRef]

21. Sulla-Menashe, D.; Kennedy, R.E.; Yang, Z.; Braaten, J.; Krankina, O.N.; Friedl, M.A. Detecting forest disturbance in the Pacific Northwest from MODIS time series using temporal segmentation. Remote Sens. Environ. 2014, 151, 114-123. [CrossRef]

22. Vicente-Serrano, S.M.; Cabello, D.; Tomás-Burguera, M.; Martín-Hernández, N.; Beguería, S.; Azorin-Molina, C.; Kenawy, A. Drought variability and land degradation in semiarid regions: Assessment using remote sensing data and drought indices (1982-2011). Remote Sens. 2015, 7, 4391-4423. [CrossRef] 
23. Huang, C.Q.; Goward, S.N.; Schleeweis, K.; Thomas, N.; Masek, J.G.; Zhu, Z.L. Dynamics of national forests assessed using the Landsat record: Case studies in eastern United States. Remote Sens. Environ. 2009, 113, 1430-1442. [CrossRef]

24. Kennedy, R.E.; Cohen, W.B.; Schroeder, T.A. Trajectory-based change detection for automated characterization of forest disturbance dynamics. Remote Sens. Environ. 2007, 110, 370-386. [CrossRef]

25. Xia, H.; Wu, J.J.; Liu, Y.N.; Fan, J.L. Progress on drought monitoring by remote sensing in China. Remote Sens. Inf. 2005, 1, 55-58.

26. Zarch, M.A.A.; Malekinezhad, H.; Mobin, M.H.; Dastorani, M.T.; Kousari, M.R. Drought monitoring by reconnaissance drought index (RDI) in Iran. Water Resour. Manag. 2011, 25, 3485-3504. [CrossRef]

27. Qu, G.; Yang, G.; Wang, Y. Drought remote sensing monitoring method. Agric. Sci. Technol. Equip. 2013, 5, 42-44.

28. Tucker, C.J.; Choudhury, B.J. Satellite remote sensing of drought conditions. Remote Sens. Environ. 1987, 23, 243-251. [CrossRef]

29. Peters, A.J.; Walter-Shea, E.A.; Ji, L.; Vina, A.; Hayes, M.; Svoboda, M.D. Drought monitoring with NDVI-based standardized vegetation index. Photogramm. Eng. Remote Sens. 2002, 68, 71-75.

30. Fensholt, R.; Sandholt, I. Derivation of a shortwave infrared water stress index from MODIS near-and shortwave infrared data in a semiarid environment. Remote Sens. Environ. 2003, 87, 111-121. [CrossRef]

31. Ghulam, A.; Qin, Q.; Teyip, T.; Li, Z.L. Modified perpendicular drought index (MPDI): A real-time drought monitoring method. ISPRS J. Photogramm. Remote Sens. 2007, 62, 150-164. [CrossRef]

32. Gu, Y.X.; Hunt, E.; Wardlow, B.; Basara, J.B.; Brown, J.F.; Verdin, J.P. Evaluation of MODIS NDVI and NDWI for vegetation drought monitoring using Oklahoma Mesonet soil moisture data. Geophys. Res. Lett. 2008, 35. [CrossRef]

33. McVicar, T.R.; Jupp, D.L. The current and potential operational uses of remote sensing to aid decisions on drought exceptional circumstances in Australia: A review. Agric. Syst. 1998, 57, 399-468. [CrossRef]

34. Carlson, T.N.; Gillies, R.R.; Perry, E.M. A method to make use of thermal infrared temperature and NDVI measurements to infer surface soil water content and fractional vegetation cover. Remote Sens. Rev. 1994, 9, 161-173. [CrossRef]

35. Kogan, F.N. Application of vegetation index and brightness temperature for drought detection. Adv. Space Res. 1995, 15, 91-100. [CrossRef]

36. Wang, P.X.; Li, X.W.; Gong, J.Y.; Song, C.S. Vegetation temperature condition index and its application for drought monitoring. In Proceedings of the IEEE 2001 International Geoscience and Remote Sensing Symposium, Sydney, Australia, 9-13 July 2001; Volume 1, pp. 141-143.

37. Wan, Z.; Wang, P.; Li, X. Using MODIS land surface temperature and normalized difference vegetation index products for monitoring drought in the southern Great Plains, USA. Int. J. Remote Sens. 2004, 25, 61-72. [CrossRef]

38. Karnieli, A.; Agam, N.; Pinker, R.T.; Anderson, M.; Imhoff, M.L.; Gutman, G.G.; Panov, N.; Goldberg, A. Use of NDVI and land surface temperature for drought assessment: Merits and limitations. J. Clim. 2010, 23, 618-633. [CrossRef]

39. Liu, Q.; Li, S.; Wu, W. The input-output status and farmer's willingness of hickory ecological management. Issues For. Econ. 2011, 6, 520-525.

40. Zhan, S.; Zhao, W.; Ye, L.; Sun, Z.; Zhou, P.; Xu, C. The series study on the alternate bearing phenomenon of Carya cathayensis in Lin An. East China Forest Manag. 2004, 4, 13-16. (In Chinese)

41. Li, M.Y. A study on changes of forest landscape patterns of Lin An in Zhejiang province. J. Nanjing For. Univ. 1999, 23, 71-74.

42. Using the USGS Landsat 8 Product. Available online: http://landsat.usgs.gov/Landsat8_Using_Product.php (accessed on 21 February 2016).

43. Chander, G.; Markham, B.L.; Helder, D.L. Summary of current radiometric calibration coefficients for Landsat MSS, TM, ETM+, and EO-1 ALI sensors. Remote Sens. Environ. 2009, 113, 893-903. [CrossRef]

44. Lu, D.; Ge, H.L.; He, S.; Xu, A.; Zhou, G.M.; Du, H.Q. Pixel-based Minnaert correction method for reducing topographic effects on the Landsat 7 ETM+ image. Photogramm. Eng. Remote Sens. 2008, 74, 1343-1350.

45. Heather, R.; Hakan, O. C-correction of optical satellite data over Alpine vegetation areas: A comparison of sampling strategies for determining the empirical c-parameter. Remote Sens. Environ. 2011, 115, 1387-1400. 
46. Li, C.; Fan, J.; Fu, X.; Fan, H. Analysis and comparison test on C-correction strategies and their scale effects with TM images in rugged mountainous terrain. J. Geo Inf. Sci. 2014, 16, 134-141.

47. Lu, D.; Moran, E.; Batistella, M. Linear mixture model applied to Amazonian vegetation classification. Remote Sens. Environ. 2003, 87, 456-469. [CrossRef]

48. Mustard, J.F.; Sunshine, J.M. Spectral analysis for earth science: Investigations using remote sensing data. Remote Sens. Earth Sci. Man. Remote Sens. 1999, 3, 251-307.

49. Van der Meer, F.; de Jong, S.M. Improving the results of spectral unmixing of Landsat Thematic Mapper imagery by enhancing the orthogonality of end-members. Int. J. Remote Sens. 2000, 21, 2781-2797. [CrossRef]

50. Xi, Z.Y.; Liu, L.J.; Lu, D.; Ge, H.L.; Chen, Y.L. Mapping of Carya cathayensis spatial distribution with linear spectral mixture model. Forest Sci. 2015, 51, 43-52. (In Chinese)

51. Qi, J.; Chehbouni, A.; Huete, A.R.; Kerrt, Y.H.; Sorooshian, S. A modified soil adjusted vegetation index. Remote Sens. Environ. 1994, 48, 119-126. [CrossRef]

52. Liu, H.Q.; Huete, A.R. A feedback based modification of the NDVI to minimize canopy background and atmospheric noise. IEEE Trans. Geosci. Remote Sens. 1995, 457-465. [CrossRef]

53. Congalton, R.G.; Green, K. Assessing the Accuracy of Remotely Sensed Data: Principles and Practice, 2nd ed.; CRC Press, Taylor \& Francis Group: Boca Raton, FL, USA, 2008.

54. Lu, D.; Weng, Q. A survey of image classification methods and techniques for improving classification performance. Int. J. Remote Sens. 2007, 28, 823-870. [CrossRef]

55. Lu, D.; Mausel, P.; Brondízio, E.; Moran, E. Change detection techniques. Int. J. Remote Sens. 2004, 25, 2365-2407. [CrossRef]

56. Lu, D.; Batistella, M.; Moran, E. Integration of Landsat TM and SPOT HRG images for vegetation change detection in the Brazilian Amazon. Photogramm. Eng. Remote Sens. 2008, 74, 421-430. [CrossRef]

57. Lu, D.; Batistella, M.; Moran, E. Multitemporal spectral mixture analysis for Amazonian land-cover change detection. Can. J. Remote Sens. 2004, 30, 87-100. [CrossRef]

58. Lehmann, E.A.; Caccetta, P.A.; Zhou, Z.S.; McNeill, S.J.; Wu, X.L.; Mitchell, A.L. Joint processing of Landsat and ALOS-PALSAR data for forest mapping and monitoring. IEEE Trans. Geosci. Remote Sens. 2012, 50, 55-67. [CrossRef]

59. Dong, J.W.; Xiao, X.M.; Chen, B.Q.; Torbick, N.; Jin, C.; Zhang, G.L.; Biradar, C. Mapping deciduous rubber plantations through integration of PALSAR and multi-temporal Landsat imagery. Remote Sens. Environ. 2013, 134, 392-402. [CrossRef]

60. Kou, W.L.; Xiao, X.M.; Dong, J.W.; Gan, S.; Zhai, D.L.; Zhang, G.L.; Qin, Y.W.; Li, L. Mapping deciduous rubber plantation areas and stand ages with PALSAR and Landsat images. Remote Sens. 2015, 7, 1048-1073. [CrossRef]

61. Li, L.; Dong, J.W.; Tenku, S.N.; Xiao, X.M. Mapping oil palm plantations in Cameroon using PALSAR 50-m Orthorectified Mosaic images. Remote Sens. 2015, 7, 1206-1224. [CrossRef]

62. Anjos, D.; Lu, D.; Dutra, L.; Sant'Anna, S. Change detection techniques using multisensor data. In Remote Sensing Handbook-Data, Characterization, Classification and Accuracies; Thenkabail, P.S., Ed.; Taylor and Francis Inc.: Oxford, UK, 2015; Volume 1, pp. 377-397.

63. Lambin, E.F. Monitoring forest degradation in tropical regions by remote sensing: Some methodological issues. Glob. Ecol. Biogeogr. 1999, 8, 191-198. [CrossRef]

(C) 2016 by the authors; licensee MDPI, Basel, Switzerland. This article is an open access article distributed under the terms and conditions of the Creative Commons Attribution (CC-BY) license (http://creativecommons.org/licenses/by/4.0/). 